\title{
TERRITORIAL DIFFERENCES IN INFANT MORTALITY IN LATVIA IN THE FIRST DECADE OF THE THIRD MILLENNIUM
}

\author{
Inguna Ebela ${ }^{1}$, Irisa Zīle ${ }^{2}$, Nadīne Muciņa ${ }^{1}$, Danute Ražuka-Ebela ${ }^{1}$, Ingrīda Rumba-Rozenfelde ${ }^{1}$ \\ ${ }^{1}$ Department of Paediatrics, Faculty of Medicine, University of Latvia, Riga, Latvia \\ ${ }^{2}$ Department of Research, Statistics and Health Promotion, Centre for disease prevention and control of Latvia, Riga, Latvia
}

\section{SUMMARY}

Objective: Infant and child mortality are some of the most substantial indicators of country welfare. Infant mortality (IM) in Latvia is constantly the highest among 25 Member States of the European Union. Since the regaining of independence in 1991, IM has decreased by almost 50\%, however, it is still high enough to cause concern that the country will not be able to meet the UN Millennium Development Goals to decrease IM in Latvia by 2015. The Medical Faculty at the University of Latvia has conducted several studies identifying correlations between IM and GDP, total expenditure on health, unemployment and GINI coefficient. It is necessary to identify all IM causes and relationships which have not been studied, including the effect of social factors causing inequality between inhabitants of urban and rural areas.

The aim of the study was to determine the IM rate and the main death causes and their differences between rural and urban areas in Latvia (2000-2010).

Materials: This is a register-based study. The data of 1994 deceased infants was analyzed over the time period from 2000-2010. The studied population was divided into two groups - urban and rural areas by mothers' area of residence. Descriptive and analytical methods were used for analysis - frequency distribution, correlation and regression analysis.

Results: IM by maternal residence as well as IM indicators in the most common diagnostic subgroups have been higher in rural areas in the entire studied period (2000-2010). The decrease proportion of IM was more rapid in rural regions with a period average of $6.2 \%$ in comparison to urban regions $-2.6 \%$. Annual decrease of IM from perinatal period conditions was $50 \%$ lower in rural than urban areas; annual decrease of IM from congenital malformations, deformations and chromosomal abnormalities was $20 \%$ lower in urban than rural areas; annual decrease in other diagnostic groups was $40 \%$ lower in urban than rural areas. During the study period, differences in infant mortality based on maternal sociodemographic factors, maternal health as well as pregnancy and obstetric history have been found, but the results of statistical analysis cannot be used to define these relationships as statistically significant in either areas.

Conclusions: Infant mortality in Latvia due to various conditions prevailing during perinatal period, external causes and sudden infant death syndrome can be substantially decreased - by improving the theoretical and technical capacity of obstetric departments in rural areas as well as educating society on preventable causes of death.

Key words: infant mortality, perinatal mortality, Latvia, regional differences, urban, rural

Address for correspondence: I. Ebela, Department of Paediatrics, Faculty of Medicine, University of Latvia, Raina bulvaris 19, Riga, LV-1586, Latvia. E-mail: inguna.ebela@inbox.Iv

\section{INTRODUCTION}

Child mortality indicators are used to assess the accessibility and quality of the healthcare system of a country as well as the overall level of welfare. Among the most important indicators are perinatal and infant mortality $(1,2)$.

Infant mortality (IM) in Latvia is constantly the highest among 25 Member States of the European Union. Although since the regaining of independence in 1991, IM has decreased by almost $50 \%$, it is still high enough to cause concern that the country will not be able to meet the UN Millennium Development Goals $(3,4)$.

Despite a decreasing tendency in IM (according to data from the WHO European Health for All Database), in comparison with other Baltic countries, the mortality rate in Latvia is the highest and does not show steady decrease (5).

In 2009, IM in Latvia was 7.8 per 1000 live births, but in the European Union IM was lower by almost a half -4.2 per 1000
(Fig. 1) (11). In 2011, IM in Latvia was 6.7 per 1000 live births, but in the European Union - 4 per 1000 live births, so a remarkable difference still prevails (5).

Perinatal mortality data from the European monitoring system (PERISTAT) indicates substantial differences in perinatal, neonatal and infant mortality among countries. Though it is a positive sign that mortality indicators of 2010 in comparison to 2004 have decreased, IM rate varies from 2.7 per 1000 live births in Iceland and Finland to 5.5 in Malta and 5.7 in Latvia (6).

Scientific literature points to differences in IM not only on a national level, but also at a regional level in each country (7-9). Latvia's routine statistics indicate regional differences in IM. In comparison to Latvia's national average in 2010 and 2011 5.7/1000 and 6.7/1000 live births, respectively, IM in different regions was significantly higher - on average by 1.5 times. For example, in Latgale (east) was IM rate 8.4/1000 and 9.4/1000, but in Kurzeme (south) it was 7.2/1000 and 9.4/1000, respectively (10). 


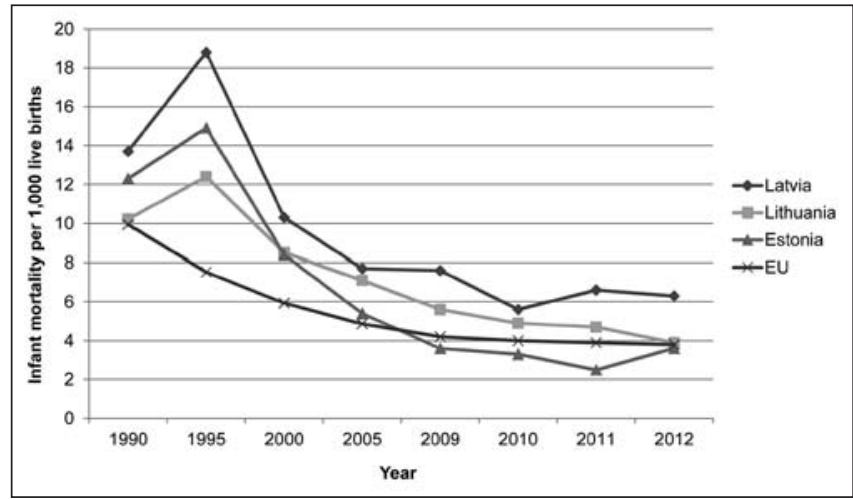

Fig. 1. Infant mortality in Latvia, Lithuania, Estonia, and the EU (1990-2012).

The study objective was to determine the infant mortality rate and the main death causes as well as the differences between rural and urban areas in Latvia from 2000-2010.

The Medical Faculty at the University of Latvia has conducted several studies, identifying correlations between IM and GDP, total expenditure on health, unemployment, and GINI coefficient $(11,12)$. It is necessary to identify all IM causes and causal relationships, including the effect of social factors, which are believed to be the main cause of inequality between inhabitants of urban and rural areas.

\section{MATERIALS AND METHODS}

This is a register-based study. Data was obtained from the Latvian Death Cause Database and Newborn Register from 2000 until 2010. In total, the data of 1,994 deceased infants was analyzed. For calculating infant mortality in urban and rural territories (deceased infants under 1 year of age per 1000 live births), supplementary data on the live birth rate in Latvia was obtained from the Newborn Register, and data on the age and education of the mother was also collected. The mothers were distributed by age into the following age groups: under 19, 20-24, 25-29, 30-34, 35 years and over.

The proportion of mortality decrease was calculated using the first year of the study (2000) as the baseline. The average rate decrease per period for the regions was calculated for each year separately, calculating the average for the period at the end. The studied population was divided into two groups - urban and rural areas by mothers' area of residence. Urban territory includes 9 largest cities in Latvia: Riga, Daugavpils, Jelgava, Jēkabpils, Jūrmala, Liepāja, Rēzekne, Valmiera, and Ventspils, while rural territory includes the respective regions with their towns and districts.

Cause-specific infant mortality was calculated in three main groups: P00-P96 (certain conditions originating in the perinatal period); Q00-Q99 (congenital malformations, deformations and chromosomal abnormalities); and other causes of death including external causes of morbidity and mortality (V01-Y98), symptoms, signs and abnormal clinical and laboratory findings, not elsewhere classified (R00-R99), diseases of the circulatory system (I00-I99), neoplasms (C00-D48), and other diagnostic groups. The International Statistical Classification of Diseases and Related Health Problems 10th version (ICD-10) was used to code causes of death.
Descriptive and analytical methods were used for analysis frequency distribution, correlation and regression analysis. The $\chi^{2}$ test was used to identify differences between categorical variables. Statistical significance was determined by confidence interval (CI) and evaluated with $\mathrm{p}$ value, $\mathrm{p}<0.05$ was considered significant.

\section{RESULTS}

From 2000 to 2010, 1,994 infants died: 54.5\% of boys $(n=1,086), 45.5 \%$ of girls $(n=908)$. No significant differences were found in the average age of mothers of the deceased infants by regions - in cities 26.4 years (SD 7.9), in countryside 25.5 (SD 8.1). However, when comparing deceased infant rate by maternal age, small differences were found between regions: mothers under $19\left(\chi^{2}=4.67 ; \mathrm{p}<0.05\right)$ and $30-34$ years $\left(\chi^{2}=4.11 ; \mathrm{p}<0.05\right)$.

Infant mortality (IM) on average 1.5 times higher was observed in rural areas in all maternal age groups. The highest IM by maternal age group was observed for mothers under 19 years - 14.0/1000 live births (95\% CI 12.1-16.2) in rural areas and 12.8/1000 (95\% CI 10.4-15.6) in urban areas. Higher IM was also observed in maternal age group of 35 and over. When comparing regional IM rate by maternal education the same situation was observed - mothers with primary education had an almost two times higher IM, which correlates with maternal age (Table 1).

\section{Infant Mortality and Changes in Urban and Rural Areas from 2000 to 2010}

The overall decrease of IM in Latvia during 2000-2010 was statistically significant $(\mathrm{p}<0.01)$, the average annual IM decrease was $0.4 / 1000$ live births $\left(y=-0.4456 x+11.267 ; R^{2}=0.83\right)$. IM has decreased from 10.39/1000 (95\% CI 9.03-11.89) in 2000 to $5.75 / 1000$ (95\% CI 4.72-6.92) in 2010. It can be observed that IM has decreased by almost a half during the studied period.

When comparing IM by region, there was different distribution during the years 2000-2010 $\left(\chi^{2}=46.13 ; \mathrm{p}<0.001\right)$.

In 2000, IM in rural areas was 10.92/1000 (95\% CI 7.82-11.99), but in urban areas slightly lower 9.75 (95\% CI 9.06-13.04). Also

Table 1. Infant mortality per 1000 live births $(95 \% \mathrm{Cl})$ in urban and rural areas of Latvia (2000-2010)

\begin{tabular}{|l|c|c|}
\hline \multirow{2}{*}{\multicolumn{2}{|c|}{}} & Infant mortality, per 1000 live births \\
\cline { 2 - 3 } \multicolumn{2}{|c|}{ Urban } & Rural \\
\hline Maternal age (years) & $12.8(10.4-15.6)$ & $14.0(12.1-16.2)$ \\
\hline Under 19 & $7.4(6.4-8.4)$ & $9.1(8.1-10.1)$ \\
\hline $20-24$ & $5.6(4.9-6.4)$ & $8.5(7.5-9.5)$ \\
\hline $25-29$ & $6.8(5.9-7.9)$ & $9.1(7.8-10.4)$ \\
\hline $30-34$ & $9.1(7.5-10.8)$ & $12.5(10.6-14.5)$ \\
\hline 35 and over & & \\
\hline Maternal education & $13.3(11.6-15.2)$ & $15.2(13.9-16.7)$ \\
\hline Elementary & $7.3(6.4-8.2)$ & $9.4(8.4-10.4)$ \\
\hline Secondary & $6.4(5.4-7.5)$ & $7.7(6.6-8.8)$ \\
\hline Secondary professional & $5.2(4.5-5.9)$ & $5.6(4.7-6.7)$ \\
\hline Higher &
\end{tabular}


at the end of the analyzed period (2010) IM was still higher in rural areas 6.20/1000 (95\% CI 4.03-6.96) than in urban areas 5.35/1000 (95 \% CI 4.67-8.07).

During the studied time period, IM decrease was observed in both areas - on average by $0.4(\mathrm{p}<0.01)$ per year per 1000 live births (Fig. 2). The decrease of IM was more rapid in rural areas, period average $-6.2 \%$ in comparison to urban areas $-2.6 \%$ (Fig. 3 and 4). A strong negative correlation $(r=-0.8 ; p<0.01)$ was observed between IM percentage decrease from 2000 to 2010 in urban areas. In 2001 and 2007, compared to the starting period (2000), an IM increase of $2.2 \%$ and $4.5 \%$, respectively, was observed (Fig. 3).

A moderate negative correlation $(r=-0.6 ; p<0.05)$ was observed between IM and percentage decrease from 2000 to 2010 in rural areas. In 2001, compared to the starting period (2000) IM increased by $4.1 \%$ (Fig. 4).

\section{Cause-specific Infant Mortality in Urban and Rural Areas}

Cause-specific IM was calculated in three main groups: conditions originating in the perinatal period (CPP), congenital malformations (CM) and other causes of death.

Cause-specific IM from CPP in the perinatal period (P00-P96) was the main cause of death in almost half of the cases $-45.3 \%$

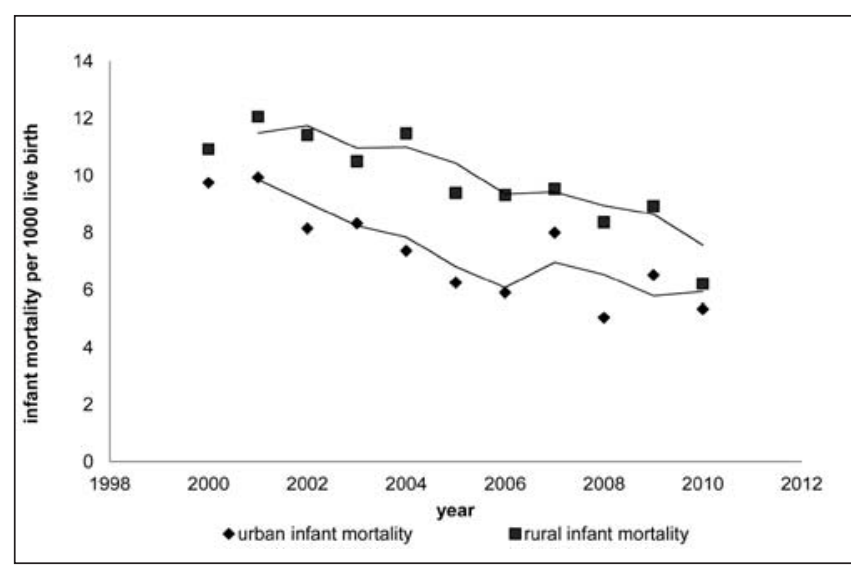

Fig. 2. Infant mortality per 1000 live births and two year average infant mortality in Latvia by urban and rural areas from 2000-2012.

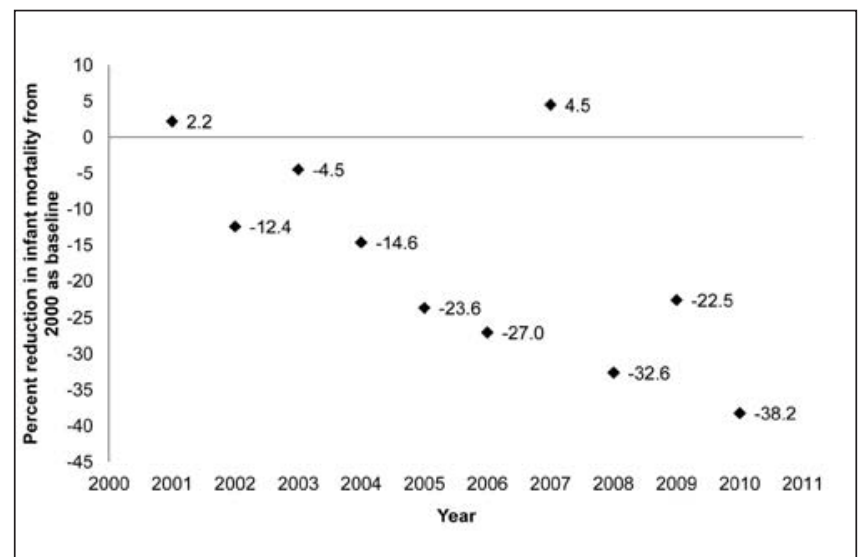

Fig. 3. Relationship between infant mortality in urban areas and the change between 2000-2010 and 2000 as a baseline.
( $n=905)$ (95\% CI 43.2-47.5). In Latvia, average cause-specific IM from CPP was 3.88/1000 (95\% CI 3.19-3.87) for the period from 2000-2010, it was higher in rural areas compared to urban areas - 4.47/1000 (95\% CI 2.94-3.61) and 3.27/1000 (95\% CI 4.09-4.86), respectively. These differences were statistically significant $\left(\chi^{2}=21.52 ; \mathrm{p}<0.001\right)$.

Decrease in IM $(\mathrm{p}<0.05)$ from CPP was observed in both areas. The average annual decrease of IM from CPP was 0.08/1000 $\left(y=-0.08 x+4.9443 ; R^{2}=0.24\right)$ in rural areas, but $0.18 / 1000$ $\left(y=-0.1808 x+4.3932 ; R^{2}=0.55\right)$ in urban areas.

Analyzing infant cause-specific IM from CM (Q00-Q99), which was in second place with $28.4 \%(n=566)(95 \%$ CI 26.4-30.4), the total IM in Latvia from 2000-2010 was 2.43/1000 (95\% CI 2.23-2.63). IM for the studied period in rural areas was slightly higher than the average in Latvia - 2.64/1000 (95\% CI 2.35-2.94), in urban areas was 2.21/1000 (95\% CI 1.95-2.50). IM decreased $(\mathrm{p}<0.01)$ by an annual average of $0.2 / 1000$, however, statistically significant differences by regions were not observed.

Comparing other causes of death $-26.3 \%(n=524)(95 \%$ CI 24.4-28.3) in the studied period, IM in this group (symptoms, signs and abnormal clinical and laboratory findings not elsewhere classified, external causes of morbidity and mortality, diseases of the nervous system, etc) was also higher in rural areas - 2.74/1000 (95\% CI 2.44-3.05), than in urban areas was 1.75/1000 (95\% CI 1.51-2.00). These differences were statistically significant $\left(\chi^{2}=25.51 ; \mathrm{p}<0.001\right)$.

When describing the most common diagnoses as causes of infant death in CPP (Fig. 5), statistically significant differences between regions were not found, but a tendency towards higher proportions was observed in rural areas. For example, IM due to respiratory and cardiovascular disorders specific to the perinatal period (P20-P29) was significantly higher in rural areas - 47.26\% (95\% CI 43.0-51.5) than in urban areas - 41.33\% (95\% CI 13.646.4). In this diagnostic group the most common registered cause of IM was unspecified birth asphyxia (P21.9), for which there was a big difference between regions, 68 deaths in urban areas compared to 107 in rural areas, which is 1.5 times higher. Also unspecified congenital pneumonia (P23.9) was a comparatively common cause of death, 30 in urban areas and 34 in rural areas, as well as respiratory distress syndrome of newborn (P22.0), 21 deaths in urban areas but 42 in rural areas.

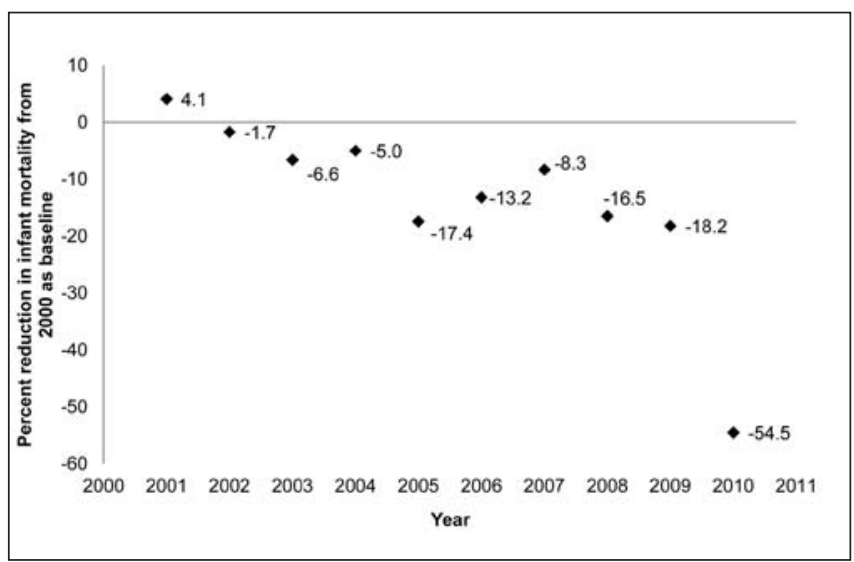

Fig. 4. Relationship between infant mortality in rural areas and the change between 2000-2010 and 2000 as a baseline. 
The second most common condition of the perinatal period was haemorrhagic and haematological disorders of foetus and newborn (P50-P61), which was registered as a cause of infant death more often in urban areas - 26.40\% (95\% CI 22.2-31.1) than in rural areas $21.74 \%$ (95\% CI 18.4-25.5). In this group the most common cause of death was unspecified intraventricular (nontraumatic) haemorrhage of foetus and newborn (P52.3).

A similar situation could be observed in relation to the most common diagnostic groups pertaining to CM (Q00-Q99) (Fig. 6). The most common cause of death in this group in both areas were congenital malformations of the circulatory system (Q20-Q29). It was higher in rural areas - 43.7\% (95\% CI 37.9-48.8) of all $\mathrm{CM}$ in rural areas compared to $40.55 \%$ (95\% CI 34.7-46.7) in urban areas. However, these differences between territories were not statistically significant (Fig. 6).

The most common congenital malformations of the circulatory system were unspecified. Congenital malformation of heart (Q24.9) was the cause of death of 33 infants in urban areas and 43 infants in rural areas. Discordant ventriculoarterial connection (Q20.3) was the cause of death of 13 infants in urban areas and 22 infants in rural areas. The second most common cause were other congenital malformations (Q80-Q89), which caused the death of $28.53 \%$ (95\% CI 23.8-33.8) of infants in rural areas

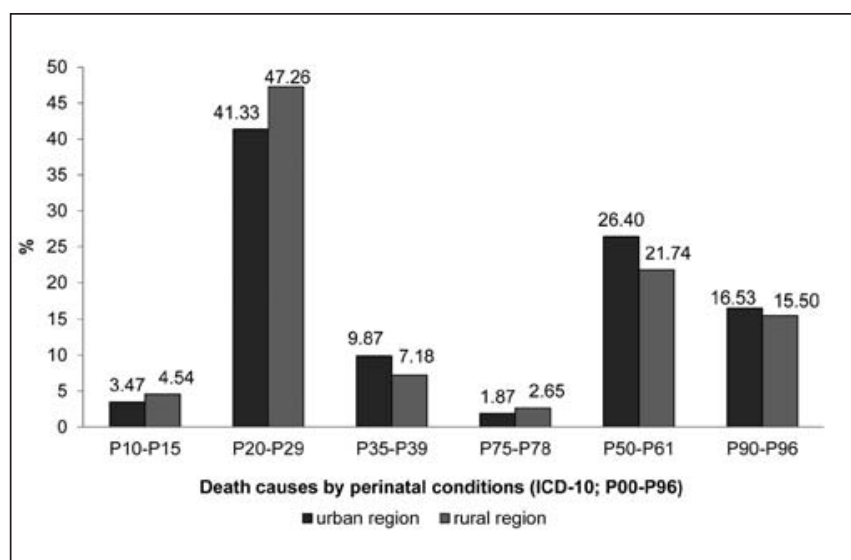

Fig. 5. Infant mortality proportion by the most common cause of death groups of certain conditions originating in the perinatal period in urban and rural areas in Latvia (2000-2010).

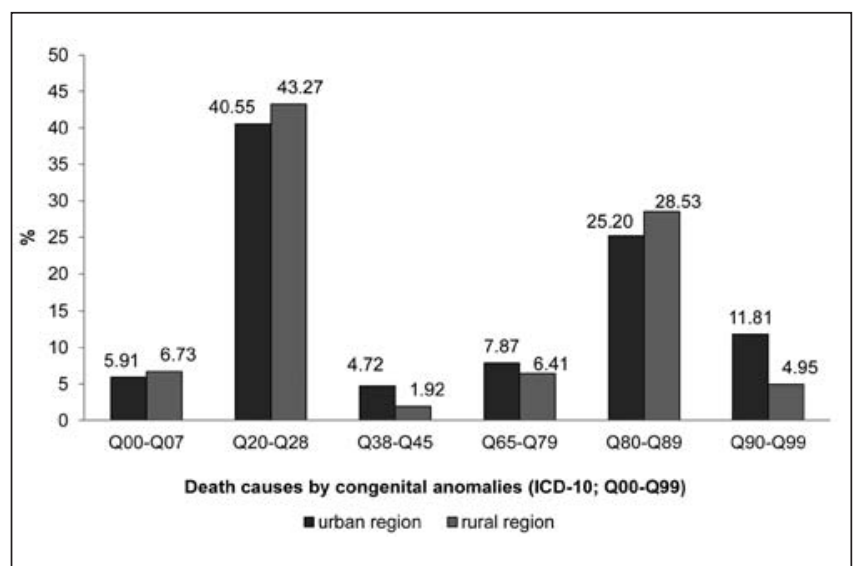

Fig. 6. Infant mortality proportion by the most common cause of death groups of congenital malformations in urban and rural areas in Latvia (2000-2010). and $25.20 \%$ (95\% CI 20.3-30.9) in urban areas. These differences were not statistically significant. Here the most common diagnosis was multiple congenital malformations not classified elsewhere (Q89.7), which was the cause of death of 44 infants in urban areas and 65 infants in rural areas. The third most common cause was Chromosomal abnormalities not classified elsewhere (Q90-Q99), which was the cause of death of 11.81\% (95\% CI 8.4-16.4) of infants in rural areas and 4.95\% (95\% CI 6.3-12.7) in urban areas. These differences were not statistically significant.

Analyzing the IM proportion in the symptoms, signs and abnormal clinical and laboratory findings not classified elsewhere (R00-R99 diagnostic group), the proportion did not significantly differ among regions - in rural areas 42.3\% (95\% CI 37.0-47.7) and urban areas 42.0\% (95\% CI 35.4-48.9). These differences were not statistically significant. In this diagnostic group the most common cause of death was sudden infant death syndrome (R95). External causes of morbidity and mortality (V01-Y98) were registered on average 2.5 times more often in rural areas $-22.2 \%$ (95\% CI 18.0-27.1) than in urban areas 15.0\% (95\% CI 10.7-20.6). However, these differences were not statistically significant.

\section{DISCUSSION}

Currently in the world almost half of all infants live in cities, the other half - in the countryside (13). In scientific literature attention has been drawn to infant mortality by maternal residence, pointing to differences in child mortality in urban and rural areas. The comparison of different publications is difficult and even contradictory, because they are influenced by differences in defining socioeconomic conditions and analytical parameters as well as the researcher's approach to study, which can be conducted at both individual and national level (14).

It must however be taken into account, that an individual does not always live and receive medical care according to their declared place of residence. This circumstance could hinder the assessment of relationships between infant mortality and social factors. Our study confirmed that there are differences in infant mortality by region in Latvia. From 2000 to 2010, infant mortality has been higher in rural areas. The reason might be better health care and accessibility of medical personnel in cities.

In Latvia, the accessibility and quality of medical care in urban and rural areas differ due to uneven distribution of regional doctors (15).

For rural inhabitants waiting lines for specialists, the lack of specialists, problems with transport and long traveling distances to medical institutions lead to a decrease in the use of health care services by the population (16). An essential aspect of decreasing infant mortality is pregnancy and its supervision in order to prevent complications, which in turn requires timely specialist visits.

Our study shows that there are cause-specific differences in IM between urban and rural areas - proportion-wise in both studied areas, the most common causes of death are certain conditions originating in the perinatal period, but in second place are congenital malformations, deformations and chromosomal abnormalities. In third place other causes of death were combined, including external causes of morbidity and mortality, diseases of the circulatory system, neoplasms, and other diagnostic groups. Other authors mention these groups as the main causes of $\operatorname{IM}(11,17,18)$. 
Our study revealed that in the most common IM diagnosis subgroups, the highest mortality was observed in rural areas. However, these results are not statistically significant, which can possibly be explained by the small amount of cases. Yet the difference by area in absolute numbers is big enough to draw attention to this tendency.

The most common causes of death of the perinatal period were respiratory and circulatory system diseases, where unspecified birth asphyxia was by $40 \%$ and respiratory distress syndrom by $50 \%$ more common in rural than urban areas. Among other disorders originating in the perinatal period neonatal cerebral ischaemia as a cause of death was more common in rural than urban areas by $30 \%$. All of these causes of death indicate a lack of prenatal, perinatal and postpartum care and show that it is necessary to carefully evaluate the work of obstetric departments. These substantial differences are possibly connected to insufficient care of pregnant women and newborns in rural areas, a statistically significant correlation between IM and ultrasonoscopic evaluation of pregnant women in regions was found (19). For a more thorough interpretation of results it would be necessary to study the birth places of the deceased infants and assess the quality of obstetric departments and the accessibility of newborn intensive therapy.

The most common subgroup of congenital malformations (CM) was that of the circulatory system, where unspecified $\mathrm{CM}$ of heart and discordant ventriculoarterial connection were more common causes of death in rural areas. The prevalence of congenital malformations was connected to inferior care of pregnant women, late registration for antenatal care, and a lack of first ultrasound examination before the 22nd gestational week, which was performed significantly less in rural areas compared to urban areas (12).

In other diagnostic groups the most common cause of infant mortality was sudden infant death syndrome, which was $40 \%$ higher in rural than urban areas, possibly due to young mothers being less educated about newborn care $(12,20)$. Our study shows that the annual decrease of infant mortality from perinatal period conditions in rural areas was lower than in cities by more than $50 \%$ in the studied period, most likely due to the lack of qualified perinatal care or its accessibility in rural areas. However, there was a lower annual decrease in cities - by $20 \%$ in infant mortality from congenital malformations, deformations and chromosomal abnormalities probably due to more risk factors, for example, the environment and maternal age. Latvian authors have found that congenital malformation prevalence positively correlates with maternal age, and this correlation is stronger in cities (14). Infants in Latvian cities had more often congenital malformations of the circulatory system, the most common cause of death in the above-mentioned diagnostic group. In the remaining diagnostic groups the annual mortality decrease in cities was $40 \%$ lower than in rural areas.

The most often mentioned social factors influencing IM are maternal age, education, family situation and obstetric history, which are in turn influenced by the environment and life style determining the health condition of the mother and thus influencing pregnancy and delivery. If in this "chain” a link is faulty, it may cause an unfavourable outcome (12, 21-24).
Highest infant mortality in both rural and urban areas was found for mothers under the age of 19, followed by mothers 35 and older. Latvia is among countries with the highest proportion of underage mothers (23).

The connection between education and IM was confirmed by the fact that mothers with a lower level of education had higher IM rates in both rural and urban areas. UNICEF points out that a child's chances of survival increase if the mother has a high school or higher education (25).

For a more thorough interpretation of the results more precise information on infant mortality by maternal residence, an evaluation of mothers' actual place of residence and individual social circumstances is necessary. It is possible that factors such as harmful habits, environmental and work factors and information about the father could influence the results of the study. For other European countries in routine statistics* such detailed data on the topic is not available (5).

\section{CONCLUSIONS}

Infant mortality by maternal residence and infant mortality indicators in the most common diagnostic subgroups were higher in rural areas during the entire studied period. Annual decrease of infant mortality from perinatal period conditions was 50\% lower in rural areas, however, in urban areas IM from congenital malformations, deformations and chromosomal abnormalities was $20 \%$ lower. Annual decrease in other diagnostic groups was $40 \%$ lower in urban areas compared to rural areas. Infant mortality in Latvia due to certain conditions of the perinatal period, external causes and sudden infant death syndrome can be substantially decreased by improving the theoretical and technical capacity of obstetric departments in rural areas, their accessibility and by educating society on preventable causes of death.

\section{Conflict of Interests}

None declared

\section{REFERENCES}

1. Ebela I, Bik̦is E, Rumba-Rozenfelde I. Under-five child mortality in Latvia: causal relationships and reduction possibilities in an international context. Scientific Papers University of Latvia. Medicine. 2009;750:8-27. (In Latvian.)

2. Phumaphi J, Evans T, Van Lerberghe W, editors. The World health report 2005: make every mother and child count [Internet]. Geneva: WHO; 2005 [cited 2013 Jun 3]. Available from: http://www.who.int/whr/2005/ whr2005_en.pdf.

3. The Millennium Development Goals report 2013 [Internet]. New York: United Nations; 2013 [cited 2013 Sep 30]. Available from: http://www. un.org/millenniumgoals/pdf/report-2013/mdg-report-2013-english.pdf.

4. United Nations Development Programme. What will it take to achieve the Millennium Development Goals? An International Assessment [Internet]. New York: UNDP; 2010 [cited 2013 Nov 23]. Available from: http:// content.undp.org/go/cms-service/stream/asset/?asset_id=2620072.

5. World Health Organization. European health for all database (HFA-DB) [Internet]. Copenhagen: WHO Regional Office for Europe [cited 2013 Mar 5]. Available from: http://data.euro.who.int/hfadb/.

6. Zeitlin J, Mohangoo A, Delnord M, editors. European perinatal health report: health and care of pregnant women and babies in Europe in 2010

\footnotetext{
*Source: United Nations demographic yearbook, 2000-2012
} 
[Internet]. EURO-PERISTAT; 2013 [cited 2013 Sep 9]. Available from: http://www.europeristat.com/images/doc/Peristat\%202013\%20V2.pdf.

7. Van de Poel E, O'Donnell O, Van Doorslaer E. What explains the ruralurban gap in infant mortality: household or community characteristics? Demography. 2009 Nov;46(4):827-50.

8. Guildea ZE, Fone DL, Dunstan FD, Cartlidge PH. Differences in risk of mortality under 1 year of age between rural and urban areas: an ecological study. Public Health. 2005 May;119(5):442-7.

9. Guildea ZE, Fone DL, Dunstan FD, Sibert JR, Cartlidge PH. Social deprivation and the causes of stillbirth and infant mortality. Arch Dis Child. 2001 Apr;84(4):307-10.

10. Latvian health and health care indicator database [Internet]. Riga: The Centre for Disease Prevention and Control of Latvia [cited 2013 Mar 5]. Available from: http://www.spkc.gov.lv/index.php?id=5. (In Latvian.)

11. Ebela I, Rumba - Rozenfelde I, Karaškēvica J, Biḳis E, Braclavska O, Daugule I, et al. Child mortality: risk factors, causal relationships, possibilities of prevention. In: Rumba- Rozenfelde I, editor. Pediatric diseases and their risk factors. Rīga: LU Akadēmiskais Apgāds; 2009. p. 144-79. (In Latvian.)

12. Ebela I, Zile I, Zakis A, Folkmanis V, Rumba-Rozenfelde I. Mortality of children under five and prevalence of newborn congenital anomalies in relation to macroeconomic and socioeconomic factors in Latvia. Medicina (Kaunas). 2011;47(12):667-74.

13. Aleshina N, Redmond G. How high is infant mortality in Central and Eastern Europe and the CIS. Innocenti working papers, no. 95 [Internet]. Florence: UNICEF Innocenti Research Centre; 2003 [cited 2013 Sept 9]. Available from: http://www.unicef-irc.org/publications/355/\#pdf.

14. Villerusa A, Zile I, Petersons A. Registration of congenital anomalies in Latvia. RSU Collection of Scientific Papers 2009. Research Articles in Medicine and Phermacy. 2010:103-6.

15. Gigele I, Rozentāle G, Skrule J, Štāle M. Justice and solidarity in health field: report on attainment of 2nd objective of public health strategy [Internet]. Rīga: Sabiedrības Veselības Aǵentūra; 2008 [cited 2013 Jun 15]. Available from: http://vec.gov.lv/uploads/files/4d00dfb53bac1.pdf. (In Latvian.)

16. Karaškēvica J. Latvian healthcare system reform and inhabitant health from 1993 to 2003 [dissertation]. Riga: Rīgas Stradiņa Universitāte; 2004. (In Latvian.)
17. Skrule J, Štāle M, Upmale S. Maternal and child health in perinatal period [Internet]. Rīga: Sabiedrības Veselības Aǵentūra; 2009 [cited 2013 Jun 15]. Available from: http://kastanis.org/uploads/0000/0186/SVA-Matesun-berna-veseliba-perinatalaja-perioda_2009.11.16-04.pdf. (In Latvian.)

18. Eurostat. Health statistics - Atlas on mortality in the European Union [Internet]. Luxembourg: Office for Official Publications of the European Communities; 2009 [cited 2013 Jun 15]. Available from: http://www. eurosfaire.prd.fr/7pc/doc/1252488295_atlas_mortalite_ue_2009.pdf.

19. Ebela I, Karaškēvica J, Ražuka-Ebela D, Rumba-Rozenfelde I. Child healthcare and health situation in Latvia - analysis of several relationships. Proceedings of the University of Latvia 69th Scientific Conference, Medical Section; 2011 Feb 3; Riga, Latvia. Riga: University of Latvia; 2011. p. 33. (In Latvian.)

20. Kliegman RM, Marcdante KJ, Jenson HB, Behrman RE. Nelson essentials of pediatrics. 5th ed. Philadephia: Elsevier Saunders; 2006.

21. Prüss-Üstün A, Bos R, Gore F, Bartram J. Safer water, better health: costs, benefits and sustainability of interventions to protect and promote health [Internet]. Geneva: WHO; 2008 [cited 2013 Sep 9]. Available from: http:// whqlibdoc.who.int/publications/2008/9789241596435_eng.pdf.

22. Mathews TJ, MacDorman MF. Infant mortality statistics from the 2005 period linked birth/infant death data set. Natl Vital Stat Rep. 2008 Jul 30;57(2):1-32

23. Zeitlin J, Mohangoo A, editors. European perinatal health report: data from 2004 [Internet]. EURO-PERISTAT; 2008 [cited 2013 Jun 15]. Available from: http://www.europeristat.com/reports/european-perinatalhealth-report2004.html.

24. Office for National Statistics. Gestation-specific infant mortality in England and Wales, 2009. Statistical Bulletin [Internet]. London: Office for National Statistics; 2011 [cited 2013 Aug 13]. Available from: http:// www.ons.gov.uk/ons/dcp171778_237668.pdf.

25. The Millennium Development Goals report 2011 [Internet]. New York: United Nations; 2011 [cited 2013 Sep 9]. Available from: http://www. un.org/millenniumgoals/pdf/\%282011_E\%29\%20MDG\%20Report\%20 2011_Book\%20LR.pdf.

Received December 1, 2013 Accepted in revised form November 30, 2014 